\title{
DESIGN AND FABRICATION OF MECHANICAL FOOTSTEP POWER GENERATOR
}

\author{
Shivendra Nandan \\ School of Mechanical Engineering, \\ Galgotias University, \\ Greater Noida, U.P., India
}

\author{
Rishikesh Trivedi \\ School of Mechanical Engineering, \\ Galgotias University, \\ Greater Noida, U.P., India
}

Abstract- Nowadays energy and power are the one of the basic needs in this modern world. Energy demand is increasing day by day. On the other hand, the many energy resources are getting exhausted and wasted. Proposal for utilization of waste energy of foot power with human locomotion is very relevant in populated countries like India where roads, railway stations, bus stands, temples, etc. are overcrowded and millions of people move around. This whole energy is wasted. If this energy made possible for utilization it will be a great invention. In this project we are converting non-conventional from just walking foot step into electrical energy. This project uses simple drive mechanism such as rack and pinion assembly. The control mechanism carries the rack \& pinion, and D.C generator to output.

In this project we are generating electrical power as nonconventional method by simply walking or running on the footsteps. Non-conventional energy system is very essential at this time to our nation. Non-conventional energy using foot step needs no fuel input power to generate the electrical power. In this project the simple drive mechanism such as rack and pinion assembly and chain drive mechanism is used for generating power by utilization of force which is obtained during the walking on steps is converted in to electrical energy with the help of mechanical L9systems. The generated power is stored by means of battery and this is used for activating the connected loads. This is one of the compact and efficient systems for generating electricity which can be easily installed in many regions.

Keywords: Footsteps, Conventional Energy, Non-conventional energy system, D.C. Generator, Rack \& Pinion, Chain.

\section{INTRODUCTION}

Proposal for the utilization of waste energy of foot power with human locomotion is very much relevant and important for highly populated countries like India and China where mobility of its masses will turn into boon in generating electricity from its footsteps.

In India, places like roads, railway stations, bus stands, are all over crowded and millions of people move round the clock. As a result large amount of power can be obtained with the use of this promising technology. This process involves number of simple setup that are installed under the walking platform. When people walk on this platform their body weight compresses the setup which rotates a dynamo or Sanyo coil and current produced is stored in dry battery. To reduce the external compression, a responsive subflooring system is installed. And while the power producing platform is over crowded with moving population, energy is produced at larger levels. Greater movement of people will generate more energy.

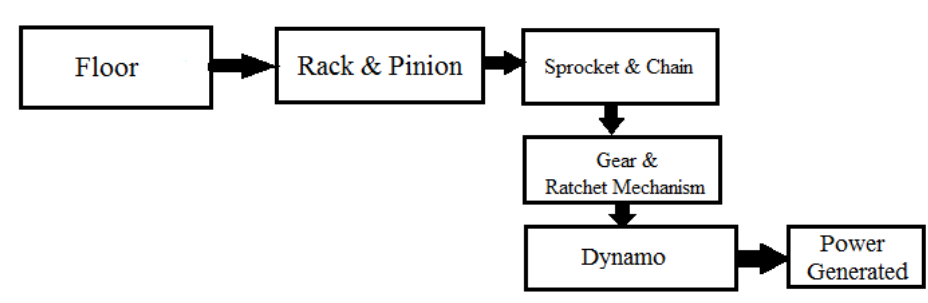

Fig. 1.1: General Block Diagram Arrangement

In this project the weight which acts on the foot step is used to generate electrical energy. When a person walks

Over the foot step, a force acts on the step. One can simply be amazed by knowing how much energy a person can have just by walking on the floor with normal speed. Whenever a person walks, manages to lose energy towards the floor by means Excess weight to the floor. That energy may be used and converted into electrical energy. The Mechanical energy (weight) is converted into electrical energy using drive mechanism, in this case rack and pinion. Generated energy can be stored in Batteries. Then the output of the battery is used to lighten the lamps in the room. Proposal for the utilization of waste energy of foot power with human locomotion is very much relevant and important. Man has needed and used energy at an increasing rate for his sustenance and well-being ever since he came on the earth a few million years ago. Primitive man required energy primarily in the form of food. He derived this by Eating plants or animals, which he hunted. Subsequently he discovered fire and his energy needs increased as he Started to make use of wood and other bio mass to supply the energy needs for cooking as well as for keeping himself Warm. With the passage of time, man started to cultivate land for agriculture. He added a new dimension to the use of Energy by domesticating and training animals to work for him. With further demand for energy, man began to use the Wind for sailing ships and for driving windmills, and the force of falling water to turn water for sailing ships and for Driving windmills, and the force of falling water to turn water wheels. Till this time, it would not be wrong to say that the sun was supplying all the energy needs of man either directly or indirectly and that man was using only renewable Sources of energy. [18] Abhishek et. al., (2016) POWER GENERATION BY FOOT STEPS USING RACK AND PINION ARRANGEMENT

This process involves number of simple setup that is installed under the walking platform. When People walk on this platform their body weight compresses the setup which rotates a dynamo and current is produced. The power producing platform is overcrowded area with 


\section{International Journal of Engineering Applied Sciences and Technology, 2019 \\ Vol. 4, Issue 05, ISSN No. 2455-2143, Pages 214-222 \\ For Publishing Online September 2019 in IJEAST (http://www.ijeast.com)}

moving population, energy is produced at larger levels. Greater movement of people will generate more energy. This whole human energy being wasted if can be made Possible for utilization it will be great invention and power producing platform will be very useful energy sources in crowded countries. Proposal for the utilization of waste energy of foot power with human locomotion is very much relevant and important. Man has needed and used energy at an increasing rate for his sustenance and well-being ever since he came on the earth a few million years ago. Primitive man required energy primarily in the form of food. He derived this by Eating plants or animals, which he hunted. Subsequently he discovered fire and his energy needs increased as he Started to make use of wood and other bio mass to supply the energy needs for cooking as well as for keeping himself Warm.

With the passage of time, man started to cultivate land for agriculture. He added a new dimension to the use of energy by domesticating and training animals to work for him. With further demand for energy, man began to use the Wind for sailing ships and for driving windmills, and the force of falling water to turn water for sailing ships and for Driving windmills, and the force of falling water to turn water wheels. Till this time, it would not be wrong to say that the sun was supplying all the energy needs of man either directly or indirectly and that man was using only renewable Sources of energy. This process involves number of simple setup that is installed under the walking platform. When People walk on this platform their body weight compresses the setup which rotates a dynamo and current is produced.

The power producing platform is overcrowded area with moving population, energy is produced at larger levels. Greater movement of people will generate more energy. This whole human energy being wasted if can be made Possible for utilization it will be great invention and power producing platform will be very useful energy sources in crowded countries.

\section{LITERATURE REVIEW}

\section{"Power Generation in Automobile Suspension System" by C. Nithiyesh Kumar, K.Gowtham, M.Manikandan, P.Bharathkanna, T. Manoj Kumar}

In this research paper author studied three methods of foot step power generation namely piezoelectric method, rack and pinion method and fuel piston method comparatively and found that the rack and pinion mechanism is more efficient with moderate cost of operation and maintenance. [1]

\section{"Generation of Electrical Energy from Foot Step Using Rack and Pinion Mechanism" by Md.Azhar, Zitender Raj purohit, Abdul Saif, Nalla Abhinay, P.Sai Chandu}

In this research paper authors used regulated $5 \mathrm{~V}$ power, $500 \mathrm{~mA}$ power supply. Bridge type full wave rectifier is used to rectify the ac output of secondary of $230 / 12 \mathrm{~V}$ step down transformer. A rack and pinion is a type of linear actuator including a pair of gears which convert rotational motion into linear motion. The "pinion" engages teeth on the rack. In this paper, since the power generation using foot step get its energy requirements from Non-renewable source of energy. There is no need of power from external sources (mains) and there is less pollution in this source of energy. It is very useful to the places like all roads and as well as all kind of foot step which is used to generate the non-conventional energy like electricity. [2]

\section{"Electrical Power Generation Using Foot Step for Urban Area Energy Applications" by Joydev Ghosh, Amit Saha, Samir Basak, Supratim Sen.}

In this research paper authors used 80 volts and $40 \mathrm{~mA}$ from one coil have been generated from a prototype model as first invention. The second invention provides 95 volts and $50 \mathrm{~mA}$ from one coil and this generated power can be used to light LED array and to run DC fan after rectifying the AC or can charge batteries. For high efficiency in the axel of the second gear, they fitted a strong magnet vertically, so that when the gear will rotate due to human body weight the magnet also rotate. The magnet is placed in a loop type copper coil. When the magnet start rotating according to the Faraday's law of electromagnetic induction, there will be induced emf in the coil. [3]

\section{"Power generation through step" by Vipin Kumar Yadav1, Vivek Kumar Yadav1, Rajat Kumar1, Ajay Yadav}

In these research paper authors used equipment with following specification: Motor Voltage:10 volt Type: D.C. Generator, RPM:1000 rpm, Gear 1-Mild Steel, No. of teeth:59(big gear),No. of teeth:36(small gear),Type: Spur Gear, No. of gear used:2 Spring 1Load bearing capacity:60-90 kg, Mild Steel, Total displacement:5 inch, Bearing 1- Type: Ball bearing, Bearing no.N35, Shaft 1Diameter: $15 \mathrm{~mm}$ - Material: Mild steel author concluded that with these method energy conversion is simple efficient and pollution free. [4]

\section{“Power Generation Footstep" by Shiraz Afzal, Farrukh hafeez}

This paper is all about generating electricity when people walk on the Floor if we are able to design a power generating floor that can produce $100 \mathrm{~W}$ on just 12 steps, then for 120 steps we can produce 1000 Watt and if we install such type of 100 floors with this system then it can produce 1MegaWattAs a fact only $11 \%$ of renewable energy contributes to our primary energy. If this project is deployed, then not only we can overcome the energy crises problem but this also contributes to create a healthy global environmental change. In this project a gear system is attached with flywheel which causes to rotate the dynamo as the tile on the deck is pressed The power that is created is saved in the batteries in addition we will be able to monitor and control the amount of electricity generated When an individual passes it push the tile on the ground surface which turn the shaft beneath the tile, turn is limited by clutch bearing which is underpinned by holders. Primary shaft is rotate 215 approx... Twice by a single tile push. The movement of the prevailing shaft turn the gearbox shaft which builds it 15 times (1:15) then its movement is smoothen by the help of fly wheel which temporary store the movement, which is convey to the DC generator (it generates $12 \mathrm{~V}$ 40 amp at $1000 \mathrm{rpm})$. [5]

\section{"POWER GENERATION FROM STEPS" by Ramesh Raja R, Sherin Mathew}

This research paper attempts to show how energy can be tapped and used at a commonly used floor step. The usage of steps in every building is increasing day by day, since even every small building has some floors. A large amount of energy is wasted when we are 


\section{International Journal of Engineering Applied Sciences and Technology, 2019 \\ Vol. 4, Issue 05, ISSN No. 2455-2143, Pages 214-222 \\ For Publishing Online September 2019 in IJEAST (http://www.ijeast.com)}

stepping on the floors by the dissipation of heat and friction, every time a man steps up using stairs. There is great possibility of tapping this energy and generating power by making every staircase as a power generation unit. The generated power can be stored by batteries, and it will be used for slighting the building. [6]

\section{"Electricity Generation from Footsteps; A Regenerative Energy Resource" by Tom Jose V*, Binoy Boban*, Sijo M $\mathbf{T}^{*}$}

In these research paper author manufactured a model made from stainless steel, recycled car tires and recycled aluminum, also includes a lamp embedded in the pavement that lights up every time a step is converted into energy (using only 5 percent of the generated energy). The average square of pavement produces about 2.1 watts of electricity. And according to author, any one square of pavement in a high-foot traffic area can see 50,000 steps a day. Based on this data, only five units of pavement can be enough to keep the lights on at a bus stop all night. [7]

\section{PROBLEM STATEMENT}

Some developing countries and newly-industrialized countries have several hours of daily power-cuts in almost all cities and villages because the increase in demand for electricity exceeds the increase in electric power generation. People in these countries may use a power-inverter (rechargeable batteries) or a diesel/petrol-run electric generator at their homes during the power-cut. The use of standby generators is common in industrial and IT hubs. This ultimately increases the shortage of power.

\section{AREA}

Design and Fabrication

\section{TITLE}

Design of Foot step power generation by using rack and pinion motion with suspension spring.

\section{AIM}

To generation the power from dynamo by using rack and pinion motion with suspension spring. Design and fabrication the model of foot step power generation. Also to fabricate the model of the same which would able to show the characteristics of the systems and working according to need.

\section{OBJECTIVE OF PROJECT}

The main aim of this project is to develop much cleaner cost effective way of power generation method, which in turns helps to bring down the global warming as well as reduce the power shortages.

\section{MOTIVATION}

Man has needed and used energy at an increasing rate for his sustenance and well-being ever since he came on the earth a few million years ago. Primitive man required energy primarily in the form of food. They derived this by eating plants or animals, which they hunted. With the passage of time, man started to cultivate land for agriculture. They added a new dimension to the use of energy by domesticating and training animals to work for them. With further demand for energy, man began to use the wind for sailing ships and for driving windmills, and the force of falling water to turn water for sailing ships and for driving windmills, and the force of falling water to turn water wheels. Till this time, it would not be wrong to say that the sun was supplying all the energy needs of man either directly or indirectly and that man was using only renewable sources of energy.

\section{OBJECTIVES}

To design and develop the model of Stair case power generation. Also fabricate the model which will work on the systems for required application.

In this project we are converting Mechanical energy into Electrical energy. We are trying to utilize the wasted energy in a useful way. By using Rack and Pinion arrangement we are converting to and fro motion of the steps into rotational motion of the dynamo.

In first foot step we are using rack and pinion arrangement directly to rotate the dynamo. But in second step we are using chain drive mechanism to obtain better efficiency. Through Dynamo the rotational energy is converted into electrical energy. This electrical energy output will be shown by glowing the LEDs. The output power is expected to be 3 to $4 \mathrm{~V}$ in prototype.

\section{COMPONENT AND ASSEMBLY}

The footstep arrangement is used to generate the electric power. Now a day's power demand is increased, so the footstep arrangement is used to generate the electrical power in order to compensate the electric power demand. In this arrangement the mechanical energy is converted into electrical energy.

This section is constructed by of rubber or other material which is placed within the surface areas. This section is mainly placed in the crowed areas. This footstep arrangement is attached with spring section.

Footstep section consists of

- Springs

- Gearwheel arrangement

- Rack and Pinion Section

- Chain drive Mechanism

- Coupling section

- Dynamo

- LEDs

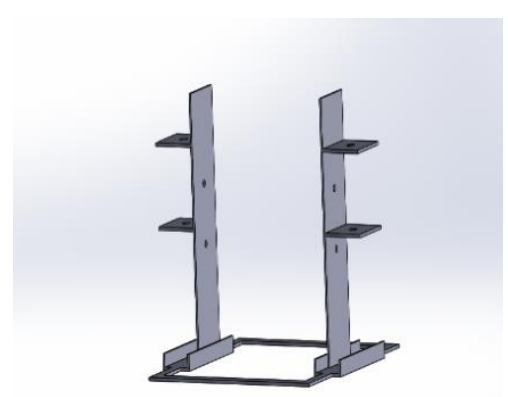

Fig 2.1.1 Base Assembly

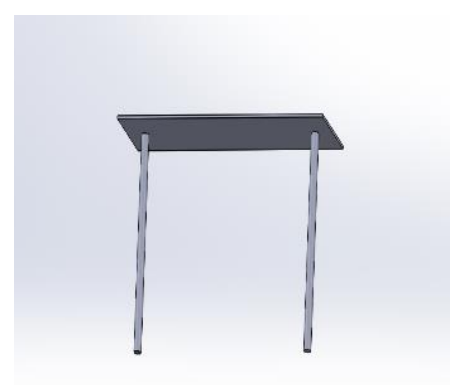

Fig 2.1.2 Upper Assembly 
International Journal of Engineering Applied Sciences and Technology, 2019

Vol. 4, Issue 05, ISSN No. 2455-2143, Pages 214-222

For Publishing Online September 2019 in IJEAST (http://www.ijeast.com)

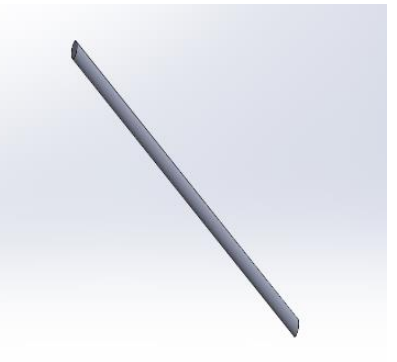

Fig 2.1.3 Shaft

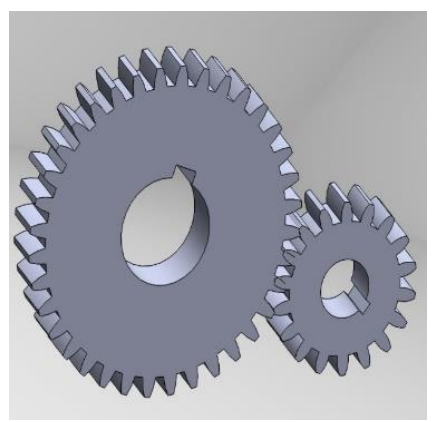

Fig 2.1.5 Spur Gears

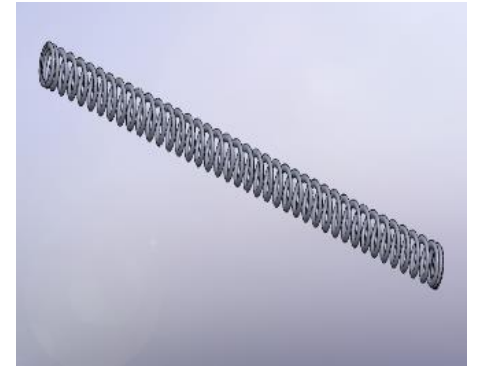

Fig 2.1.4 Spring

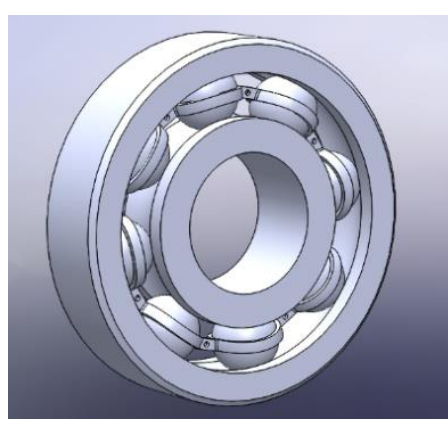

Fig 2.1.6 Bearing

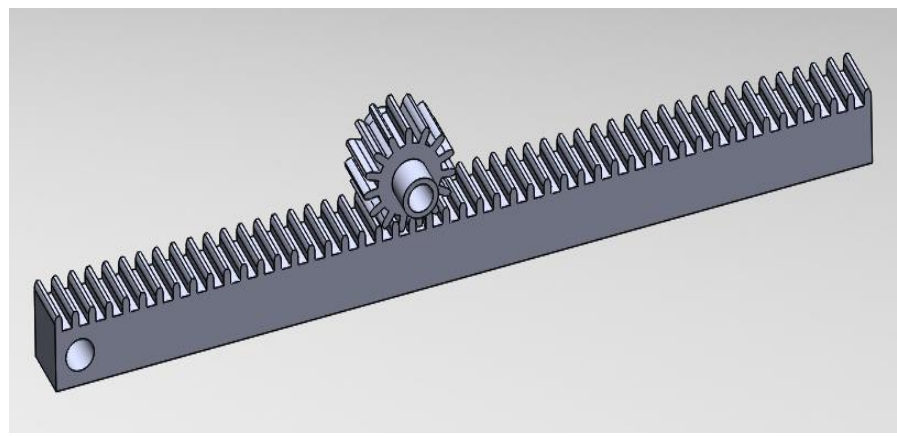

Fig 2.1.7 Rack and Pinion

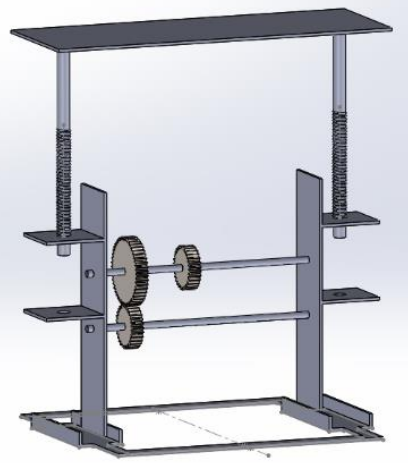

Fig 2.1.8 Assembled View
Table 2.1. Specifications

\begin{tabular}{|c|l|l|}
\hline Sr.No. & Component & Details \\
\hline $\mathbf{1 .}$ & Base and upper plate & Mild steel \\
\hline $\mathbf{2 .}$ & Fixed Cylindrical pipes & MS pipes \\
\hline $\mathbf{3 .}$ & Moving pipes & MS pipes \\
\hline $\mathbf{4 .}$ & Springs & Alloy Steel Wire \\
\hline $\mathbf{5 .}$ & Rack and pinion & Cast iron, \\
\hline $\mathbf{6 .}$ & DC motor & Electric equipment \\
\hline $\mathbf{7 .}$ & Stair frame & MS \\
\hline
\end{tabular}

The rack \& pinion, spring arrangement is fixed at the inclined step. The spring issued to return the inclined step in same position by releasing the load. The pinion shaft is connected to the supporter by end bearing. The larger sprocket also coupled with the pinion shaft, so that it is running at the same speed of piston. The larger sprocket is coupled to the small cycle sprocket with the help of chain.

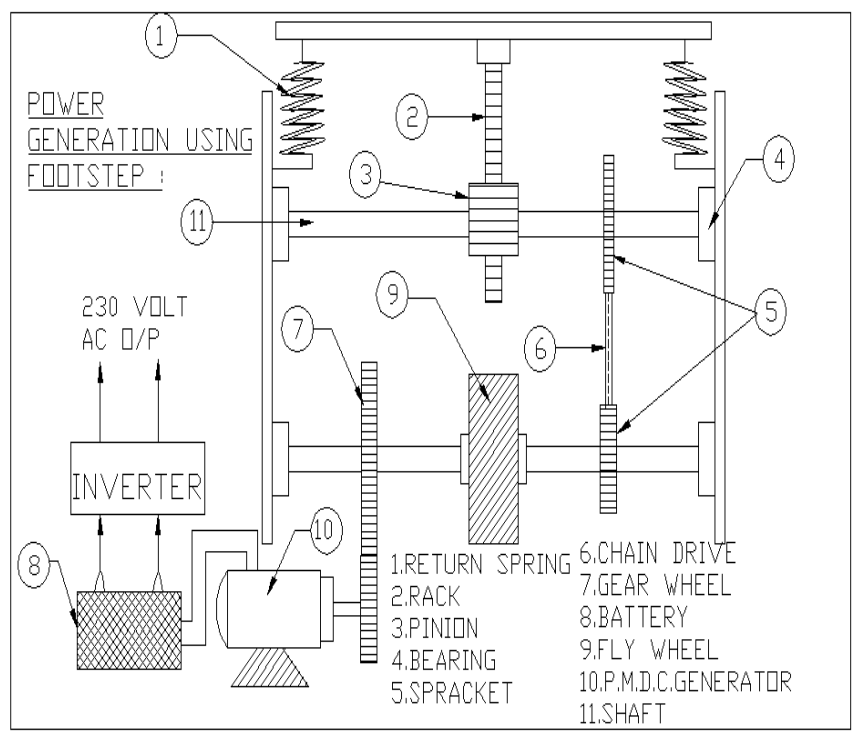

Fig. 2.1. Assembled view of components

The complete fabricated model picture of Foot Step is shown. The upper plate is mounted on two springs; the weight impact is converted into electrical power with proper control unit. The spring and rack \& pinion arrangement is fixed below the foot step which is mounted on base. Spring system is used for return mechanism of upper plate after release of load. The shaft along with pinion is supported by end bearings. A gear is provided there also. A gear is coupled to the shaft. The gear wheel which is provided in shaft is coupled to the Dynamo. The dynamo capacity used here is $12 \mathrm{~V}$. From the dynamo the wires are taken. These wires are connected to a LEDs, to show the output power. The generator is used here is 12 Volt permanent magnet DC generator. The terminal of DC generator is connected to lightning LEDs. 


\section{International Journal of Engineering Applied Sciences and Technology, 2019}

Vol. 4, Issue 05, ISSN No. 2455-2143, Pages 214-222

For Publishing Online September 2019 in IJEAST (http://www.ijeast.com)

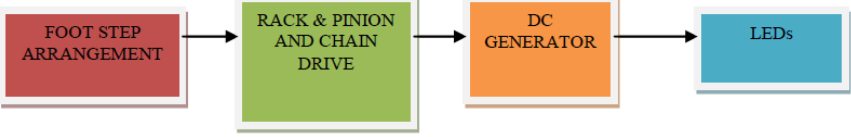

Fig. 2.2. Working Block Diagram

In the first step the footstep is directly connected to the Rack \& pinion arrangement. To the pinion shaft dynamo is provided and LEDs are coupled to it. Thus, Mechanical energy is converted in to Electrical energy.

With the help of block diagram as show in the block diagram the working procedure is explained in step by step manner.

In this project we are converting Mechanical energy into Electrical energy. We are trying to utilize the wasted energy in a useful way. By using Rack and Pinion arrangement we are converting to and fro motion of the steps into rotational motion of the dynamo.

In first foot step we are using rack and pinion arrangement directly to rotate the dynamo. But in second step we are using chain drive mechanism to obtain better efficiency.

\section{THE WORKING OF THE PROJECT}

The General design of the foot step power generation is given in fig.4.2. In this arrangement we are using two steps. The rack $\&$ pinion, spring arrangement is fixed below the steps. We are using four springs foe each step. The spring is used to return the step-in same position by releasing the load. The rack is coupled to the foot step.

In the second step, the Rack is connected to the footsteps. From Rack a shaft is provided in which the larger sprocket lies. The larger sprocket is coupled with Rack, so that it is running at the same speed of Rack. The larger sprocket is coupled to the smaller sprocket below in the other shaft with the help of chain (cycle). This larger sprocket is used to transfer the rotation force to the smaller sprocket. A gear is provided there also. The smaller sprocket is running same direction for the forward and reverse direction of rotational movement of the larger sprocket. It running at same speed also.

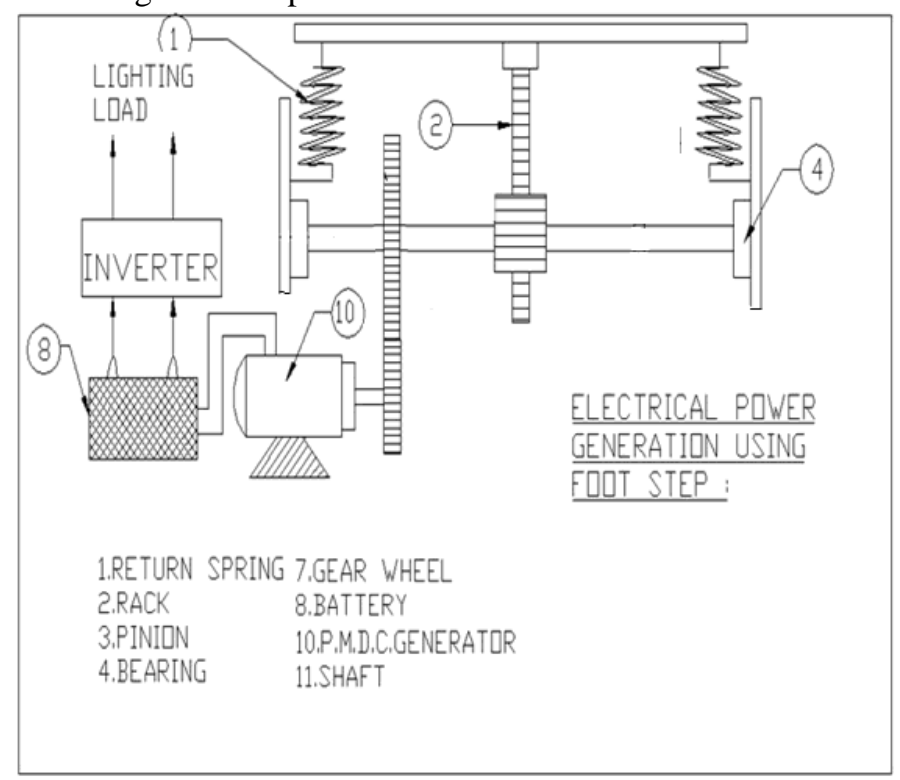

Fig: 2.3. Line Diagram for Foot Step Power Generation

The upper plate is mounted on two springs; the weight impact is converted into electrical power with proper control unit.

The spring and rack \& pinion arrangement is fixed below the foot step which is mounted on base. Spring system is used for return mechanism of upper plate after release of load. The shaft along with pinion is supported by end bearings the complete diagram of the footstep power generation is given below. Only one step is inclined in certain small angle which is used to generate the power. The pushing power is converted into electrical energy by proper driving arrangement.

The main phenomenon on which the working of this project is based is that rack and pinion assemble converts the linear motion into rotary motion and vice versa also. The pinion is of finite diameter and gives circular motion when the rack of infinite diameter comes in contact with pinion and gives linear or translator motion for proper contact between both rack and pinion the should have equal module. The shafts of rack and pinion remains parallel during their motion.

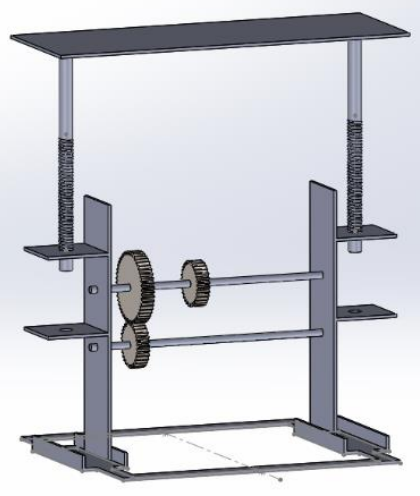

Fig. 2.4. Model Diagram

The complete and real image of this project and mechanism is shown in fig 3 given below. The impact load is put on surface on the step. One end of spring is attached to the other surface of step (plate) and another end is fixed to the stand. Firstly, the spring is compress down due to impact of load. During this process the energy is absorb in the spring. When the weight is removed from the top of the plate, the spring come back to its original position. By releasing the energy inside it and the plate moves upward and return its original position.

When the spring is compressed due to impact of weight on plate, the energy absorbed in the spring and the rack move downward direction vertically and the rack is in contact with pinion. So, pinion rotates in anti-clock wise direction. The pinion shaft is directly coupled with dynamo (generator). So, dynamo generates electricity. When the spring expends releasing the energy stored inside it, the rack moves in upward direction vertically and the rack is in contact with pinion. So, pinion rotates in clock wise direction. The pinion shaft is directly coupled with dynamo. So, dynamo generates electricity again.

If we want to store the electrical energy for future use, we connect the dynamo to the invertor which store the energy in the form of D.C. in the battery. [2] Munaswamy et. al., (2018) Mechanical Footstep Power Generation.

The following steps are involved in the process: 


\section{International Journal of Engineering Applied Sciences and Technology, 2019 \\ Vol. 4, Issue 05, ISSN No. 2455-2143, Pages 214-222 \\ For Publishing Online September 2019 in IJEAST (http://www.ijeast.com)}

Step 1: When force is applied on the plate by virtue on stamping on the plate the force spring gets compressed.

Step 2: Due to this the rack moves vertically down.

Step 3: The pinion meshed with the rack gear results in circular motion of the pinion gear.

Step 4: For one full compression the pinion Moves one semicircle, when the force applied on the plate released the pinion reverses and moves another semicircle.

Step 5: The intermediate gear with a greater number of teeth will rotate as a result of motion of pinion.

Step 6: The generator attached to the intermediate will obtain the rotating motion, hence results in the sinusoidal waveform (for single Generator).

Step 7: The voltage signal thus obtained will be displayed in LCD display about how much voltage of current is available.

\section{OUTPUT POWER CALCULATION}

Let us consider,

The mass of a body $=65 \mathrm{Kg}$ (Approximately)

Height of spring $=8 \mathrm{~cm}$

$\therefore$ Work done $=$ Force $\mathrm{x}$ Distance

Here,

Force $=$ Weight of the Body

$$
=65 \mathrm{Kg} \times 9.81
$$$$
=637.65 \mathrm{~N}
$$

Distance traveled by the body $=$ Height of the spring

$$
\begin{aligned}
& =8 \mathrm{~cm} \\
& =0.08 \mathrm{~m}
\end{aligned}
$$

$\therefore$ Output power $=$ Work done $/ \mathrm{Sec}$

$$
\begin{aligned}
& =(637.65 \times 0.08) / 60 \\
& =0.8502 \text { Watts } \\
& \text { (For One pushing force) }
\end{aligned}
$$

\section{FLOORING SYSTEM}

When the mechanical setup is used as it is, every single setup will compress separately and give an awkward feeling while walking over that. To prevent this, a flooring system is installed over the mechanical setup. The purpose of installing this flooring system is to provide required compression and at the same time to prevent the people to feel uncomfortable when walking over it. As every block over the setup is connected to one another using hinge arrangement, the compression will not be felt as the weight of the person walking over that will be distributed. But the pressure required to compress the setup will be conveyed as the person's weight acts on the particular setup only depending upon the average weight over a locomotive area, the strength and number of hinges are used. For the area where average weight is more, the numbers of the hinges are increased. This along with the primary spring provides the required compression for the setup. This hinge arrangement distributes the weight of the person and prevents them from feeling the compression. But about $95 \%$ of the pressure applied due to the weight is conveyed for the compression. [1] Bhosale et. al., (2017) "Design of Foot Step Power Energy Generation
Machine"

\begin{tabular}{|c|c|c|c|}
\hline $\begin{array}{l}\text { SR } \\
\text { NO. }\end{array}$ & COMPONENT & DETAILS & COST in ₹ \\
\hline 1. & $\begin{array}{l}\text { Base plate and upper } \\
\text { plate }\end{array}$ & $\begin{array}{l}\text { Mild steel - } \\
300 \times 300 \mathrm{~mm} \\
(300 \times 2)\end{array}$ & 1000 \\
\hline 2. & $\begin{array}{l}\text { Fixed Cylindrical } \\
\text { pipes }\end{array}$ & $\begin{array}{l}\text { M.S. pipes,30mm } \\
\text { dia. }-100 \mathrm{~mm} \\
\text { length }(100 \times 4)\end{array}$ & 400 \\
\hline 3. & Moving pipes & $\begin{array}{l}\text { MS pipes, } 20 \mathrm{~mm} \\
\text { dia.100mm length } \\
(100 \times 4)\end{array}$ & 400 \\
\hline 4. & Springs & $\begin{array}{l}\text { Alloy Steel Wire } \\
(100 \times 4)\end{array}$ & 400 \\
\hline 5. & Stair frame & MS l angle frame & 1000 \\
\hline 6. & Rack and pinion & $\begin{array}{c}\text { Cast iron, module } \\
1.5\end{array}$ & 1100 \\
\hline 7. & DC motor & 12 volt,60 rpm & 250 \\
\hline 8. & Fabrication & $\begin{array}{l}\text { Cutting, welding } \\
\text { etc. }\end{array}$ & 600 \\
\hline 9. & Assembly & $\begin{array}{l}\text { Mounting, fixing } \\
\text { motor shaft with } \\
\text { pinion. Adjusting } \\
\text { rack and pinion } \\
\text { etc. and final } \\
\text { welding }\end{array}$ & 500 \\
\hline
\end{tabular}
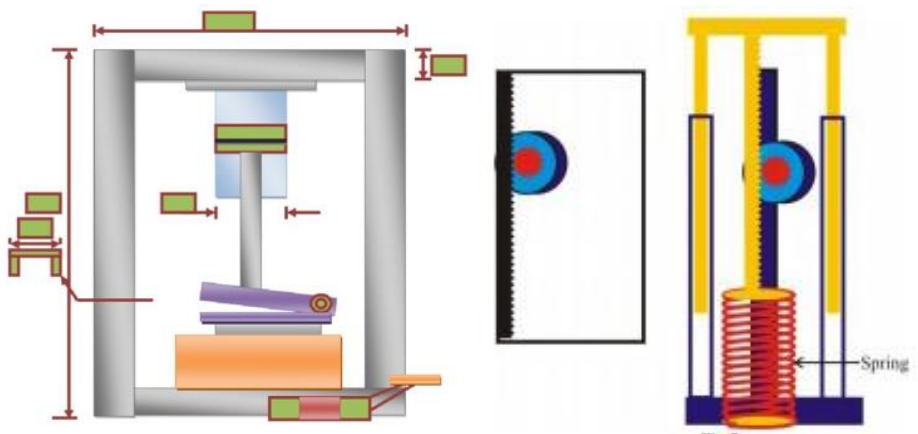

Fig. 2.5. Flooring System

XIV. ESTIMATED PROJECT COST

Table 2.2: Cost Estimation Table

XV. (i) ECONOMICAL FEASIBILITY

This device is completely in the favor of Human economy; its components are not so expensive and can be easily installed. By using this device we can save electric energy and part of money in schools, cinemas, station, etc.

\section{(ii) ENVIRONMENTAL FEASIBILITY}

The materials and the components used in it is completely also in the favor of environment and any type of pollution is not be created. The materials used in this device are not harmful to the nature components in any way.

\section{ADVANTAGES OF THE PROJECT}

This process depends on human resources which is available in 


\section{International Journal of Engineering Applied Sciences and Technology, 2019 \\ Vol. 4, Issue 05, ISSN No. 2455-2143, Pages 214-222 \\ For Publishing Online September 2019 in IJEAST (http://www.ijeast.com)}

plenty in our country which makes our country a favorable place for this project.

1) This is a Non-conventional system

2) No need fuel input.

3) Power generation is simply walking on the step.

4) Power also generated by running or exercising on the step.

5) Battery is used to store the generated power.

6) No pollution content is produced

7) It is fully eco friendly

8) Easy construction

9) It can be used at any time when it necessary

10) Easy maintenance because of less moving parts.

11) Highly efficient in more crowded places.

12) Depending upon the power generator and number of them, power output is very high

13) Promising technology for solving power crisis to an affordable extent.

14) Low cost level.

15) Reduces transmission losses.

16) Wide areas of application.

17) Maintenance cost is low.

18) Conversion of mechanical energy into electrical energy is easy.

\section{PRINCIPLE BASED APPLICATIONS}

(i) Power Generating Shoe [2] Munaswamy et al., (2017) Mechanical Footstep Power Generation

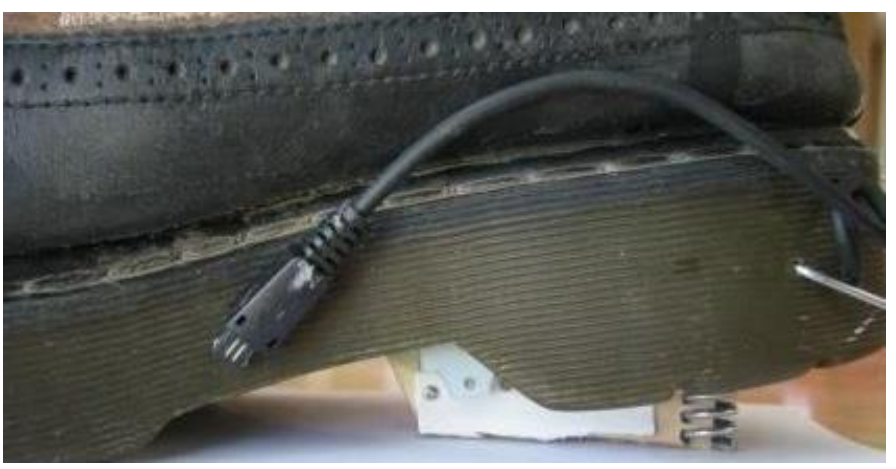

Fig. 3.1.(a) View of arrangement in Power Generation shoe

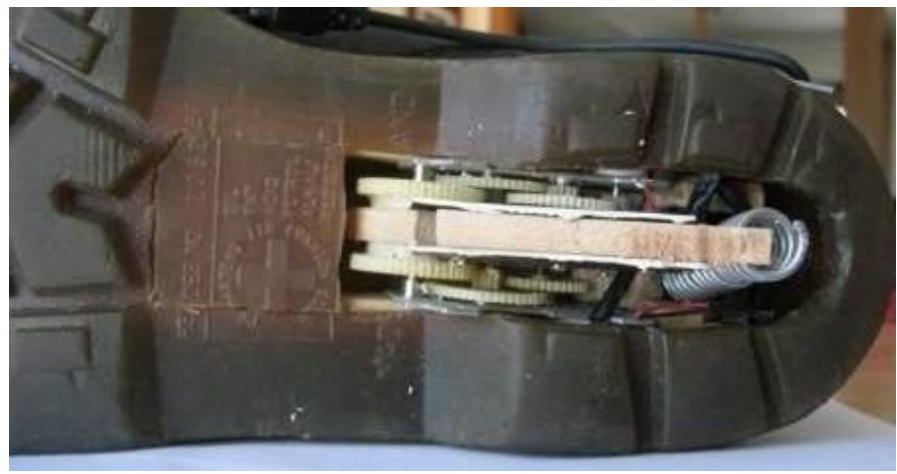

Fig. 3.1.(b) View of arrangement in Power Generation shoe

(ii) Power Generation by Speed Breaker Through Gear Mechanism [4] Dhinar et al., (2017) Footstep Power Generation System

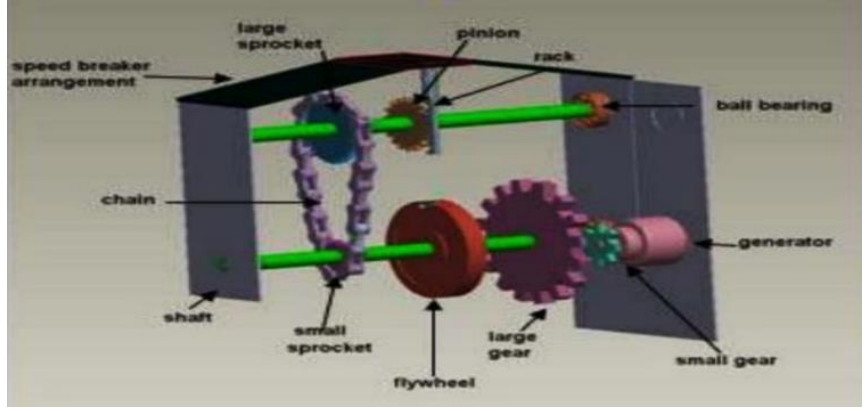

Fig. 3.2. Model of Speed Breaker Mechanism

XVIII. GENERAL APPLICATIONS

- Railway, subway stations

- Roads

- Temples

- Bus stands, air ports

- Music halls, auditoriums

- Markets

- In bus station.

- In car parking system.

- In Airports.

- In Lift system.

- In car lifting system.

- In street lights and Electric escalator

This can be implemented on railway station to generate electric power and in all places where movement of people is abundant.

\section{- Present Conflict}

\section{CONCLUSION}

Footstep power generation system produces electricity by utilizing energy which is wasted through walking. Mechanism like rack and pinion and piezo-electric material are integrated to produce desired output. Cost of electricity generation solely depends upon the initial cost, maintenance cost and life of system. Maximum advantage of this system can be taken if installed in highly dense area.

Since in this project of power generation there is not any fuel input requirement for the generation of electrical power. Thus, it can also be concluded that this mode of power generation system is ecofriendly, i.e., no pollution is caused during the generation of power using this type of model. Hence due to such advantages, this system can be embedded at any of the public places like railway platforms, busy foot-paths, malls etc.

Implementing this system, we can easily reduce our dependency on the conventional sources of energy, thus can be considered beneficial from that point of view.

It is able to extend this project by using same arrangement and construct in the footsteps/speed breaker so that increase the power production rate by fixing school and colleges, highways etc. Footstep power generation system produces electricity by utilizing energy which is wasted through walking. Mechanism like rack and pinion and piezo-electric material are integrated to produce desired output. Cost of electricity generation solely depends upon the initial cost, maintenance cost and life of system. Maximum advantage of this system can be taken if installed in highly dense area.

\section{- Future Scope}

The project work "Power generation by foot step" is designed and 


\section{International Journal of Engineering Applied Sciences and Technology, 2019 Vol. 4, Issue 05, ISSN No. 2455-2143, Pages 214-222 \\ For Publishing Online September 2019 in IJEAST (http://www.ijeast.com)}

developed successfully, for the demonstration purpose a proto type module is constructed with lower ratings of devices, \& results are found to be satisfactory. As it is a demo module it cannot be used for real applications, but the concept is near to the real working system, to make it more realistic, higher rating power generator with suitable gear mechanism is essential to produce more energy.

This concept falls under the subject of non-conventional energy resources, out of the many alternative energy resources one dependable source is solar energy, but it is quite costliest affair. Therefore alternative cheapest source is to generate electricity from foot step. This technology proven here is the ultimate inexpensive source of all known forms of energy. When it is implemented practically, depending up on the size $\&$ traffic flow, each foot step may produce tens of kilowatts power every day, this power can be utilized for many applications. If we are used this project at very busy stairs palace then we produce efficient useful electrical for large purposes. One important advantage of producing energy through this technology is that it does not pollute the environment. Hence these foot step can be altered with this technology, there by all the street lights belongs to a particular city can be energized.

\section{ACKNOWLEDGEMENT}

We are over helmed in all humbleness and gratefulness to acknowledge our depth to all those who have helped me to put these ideas, well above the level of simplicity and into something concrete.

We would like to express our sincere gratitude to our Guide Mr. K. K. Dubey \& Co Guide Mr. P.K. Chaudhary for providing their invaluable guidance, comments and suggestions throughout the course of the project. We have taken efforts in this project. However, it would not have been possible without the kind support and help of many individuals and organization Faculties. Whose guidance, encouragement, Suggestion and very constructive criticism have contributed immensely to the evolution of Ideas on Project. we would like to extend our sincere thanks to all of them.

We are highly indebted to Project Co-ordinator Mr. Abdul Gani for their guidance and constant supervision as well as for providing necessary information regarding the project \& also for their support in completing the project.

We would like to express my gratitude towards Faculty member of Galgotias University for their kind co-operation and encouragement which help me in completion of this project.

We would like to express my special gratitude and thanks to Lab and Workshop In-charges for giving me such attention and time.

Our thanks and appreciations also go to my colleague in developing the project and people who have willingly helped me out with their abilities.

and helped me a lot in gathering different information, collecting data and guiding me from time to time in making this project, despite of their busy schedules , they gave me different ideas in making this project unique.

\section{REFERENCES}

[1] Bhosale Prof. P.A., Shinde Mr.Harshal, Tahade Mr.Rohit, Valani Mr. Meet, Wallalwar Mr.Rohan, (2017) "Design of Foot Step Power Energy Generation Machine", OInternational Conference on Ideas, Impact and Innovation in Mechanical Engineering (ICIIIME 2017), ISSN: 2321-8169 /943 - 948, Volume: 5 Issue: 6

[2] Munaswamy B., Prudhvi Ch., Srikanth V., Kirankumar B., Kumar Er. Pradeep, (2018) Mechanical Footstep Power Generation, India International Journal of Engineering Trends and Applications (IJETA) - Volume 5 Issue 2, Mar-Apr 2018

[3] V. Jose Ananth Vino, (2011) Bharath University, Power Generation Using Foot Step, International Journal of Engineering Trends and Technology (IJETT) - Volume1 Issue2 - May 2011 .

[4] Dhimar Mrs. Krupal, Patel Krishna, Patel Zeel, Pindiwala Nisha, (2017) FOOTSTEP POWER GENERATION SYSTEM International Research Journal of Engineering and Technology Volume: 04 Issue: 04 | Apr -2017.

[5] Shiraz Afzal, Farrukh hafeez, (2014) Power Generation Footstep* . International Journal of Advancements in Research \& Technology, Volume 3, Issue 4, April-2014 ISSN 2278-7763.

[6] kumar Shubham, kumar Pankaj, kumar Rishav, (2016) Power Generation Footstep International Journal of Mechanical Engineering and Technology (IJMET) Volume 7, Issue 2, MarchApril 2016, pp. 187-190, Article ID: IJMET_07_02_020.

[7] Motey Yogesh, Dekate Pooja, Dekate Madhushri, Aswale Jayashree, (2017 ) Footstep Power Generation System, International Journal of Innovations in Engineering and Science, Vol. 2, No.6.

[8] Tom Jose V, Binoy Boban, Sijo M T, (2013) "Electricity Generation from foot steps; A generative Energy Resources" International Journal of Scien tific and research publication, pp 1-3, March 2013.

[9] Magdum P. R., Chikhale S. J., Rajole A. S., Jedhe S. S.,(2012) Generation of Electricity by Using Footsteps as a Source of Energy IOSR Journal of Mechanical and Civil Engineering (IOSR-JMCE) e-ISSN: 2278-1684,p-ISSN: 2320-334X PP. 50-56.

[10] Rao A.Padma, Kumar A.Kiran and S.Suresh, (2014) "Power Generation from Speed Breaker by Rack and Ratchet Mechanism", International Journal of Current Engineering and Technology, Vol. 1 No. 2, 2014. E-ISSN 2277 - 4106, P-ISSN 2347-5161

[11] Abhishek N, Shivasharana Yalag, (2016) "Power Generation by Foot Steps Using Rack and Pinion Arrangement", International Journal of Engineering Research and Advanced Technology, volume 02 Issue 01, pp 2454-61352016.

[12] Ghosh Joydev, Sen Supratim, Saha Amit, Basak Samir, (2013) "Electrical Power Generation Using Foot Step for Urban Area Energy Applications", International Conference on Advances in Computing, Communications and Informatics, 2013 IEEE.

[13] M. ISWARYA, G. R. P. Lakshmi, (2017) "Generation of Electricity by Using Speed Breakers", IEEE International 


\section{International Journal of Engineering Applied Sciences and Technology, 2019 \\ Vol. 4, Issue 05, ISSN No. 2455-2143, Pages 214-222 \\ For Publishing Online September 2019 in IJEAST (http://www.ijeast.com)}

Conference on Power, Control, Signals and Instrumentation Engineering, IEEE 2017.

[14] N. S. Metalia, D. Khandwala, (2017) "Power Generation from Dance Floor", International Journal of Engineering Research and Technology, Volume 06 Issue 04, pp 853-856 April-2017.

[15] Datta Rajesh Kumar, Rahman Sazid, (2014) "Power Generating Slabs: Lost Energy Conversion of Human Locomotive Force into Electrical Energy", $8^{\text {th }}$ International Conference on Electrical and Computer Engineering, 20-22 December, 2014, Dhaka, Bangladesh.

[16] Megalingam Rajesh Kannan, Nair Lekshmi M., Viswanath Meera, Sugathan Shreeja, (2012) "Pedalite: Lighting Up Lives in Un-electrified Villages", IEEE Global Humanitarian Technology Conference, IEEE 2012.

\section{Published in Journals}

[17] Gothane Ajinkya V., Gosavi Akshay R., Raut Prof. P. V., (2018) "Foot Step Power Generation" International Research Journal of Engineering and Technology (IRJET) e-ISSN: 23950056, p-ISSN: 2395-0072 Volume: 05 Issue: 12| Dec 2018

[18] N. Abhishek, Yalagi Shivasharana, (2016) "Power Generation By Foot Steps Using Rack And Pinion Arrangement" International Journal of Engineering Research And Advanced Technology (IJERAT) nISSN: 2454-6135 [Special Volume. 02 Issue.01, May-2016]

\section{Published in Conference Proceedings}

[19] Sahoo Sarat Kumar, Shubham kumar, Yadav Pankaj Kumar, Kumar Rishav, (2016) "Foot Step Power Generation", International Journal of Mechanical Engineering and Technology (IJMET) Volume 7, Issue 2, March-April 2016, pp. 187-190, Article ID: IJMET_07_02_020 Available online at http://www.iaeme.com/IJMET/issues.asp?JType=IJMET\&VTy pe=7\&IType=2 Journal Impact Factor (2016): 9.2286 (Calculated by GISI) www.jifactor.com ISSN Print: 0976-6340 and ISSN Online: 0976-6359

[21] Sarnaik Mr. Vishwanil V., Karnewar Mr. Akshay P., Jidge Mr. Akshay S., Pawar Mr. Tejas P.(2017) "Footstep Power Generation", GRD Journals- Global Research and Development Journal for Engineering | Volume 2 | Issue 7 | June 2017 ISSN: $2455-5703$

[22] KUMAR SHUBHAM, MITTAL SHARAD, SAINI SACHIN, PAL VISHNU., (2016) FOOT STEP ENERGY CONVERSION SYSTEM, International Journal of Scientific \& Engineering Research, Volume 7, Issue 5, May-2016 132 ISSN 2229-5518

\section{Published in Thesis}

[23] Borkar Sanket, Tripathi Ankit, Chandrikapure Amit, Dhekwar Gitesh, Bhirange Bhavesh, Kathoke Kunal, (2018) "Design and Fabrication of Foot Step Power Generator" March 2018 | IJIRT | Volume 4 Issue 10 | ISSN: 2349-6002

[24] Sabarish R , Kumar Alok, (2017) "Design And Fabrication Of Foot Step Power Gentration" International Journal of Pure and Applied Mathematics Volume 116 No. 19 2017, 529-533
ISSN: 1311-8080 (printed version); ISSN: 1314-3395 (on-line version) url: http://www.ijpam.eu, Special Issue

\section{Published in Technical Reports}

[25] Yadav Vikram, Mishra Aditya, Abhay Narayan, Devkinandan Paliwal, Deependra Sharma, A PRESENTATION ON "FOOTSTEP ELECTRICITY GENERATOR” , Carrier Point University, Kota, Rajasthan.

[27] Foot step power generation system Prepared by Amar ]"SEMINAR ON FOOTSTEP POWER GENERATION", Presented by G.DHANUNJAYA, Job antony.

[28] GARG VINAY KUMAR, Er. Arshdeep Singh “A MAJOR PROJECT REPORT ON POWER GENERATION BY FOOT STEP”, Baba Farid College Of Engineering \&Technology, Deon, Bathinda, Punjab. 